\title{
From Second Chance Learners and Second-Class Citizens to Competent Addiction Practitioners
}

\author{
Tony Carton \\ Wellington Institute of Technology, Auckland, New Zealand \\ Email: ton y.carton@weltec.ac.nz
}

How to cite this paper: Carton, T. (2018).

From Second Chance Learners and Second-Class Citizens to Competent Addiction Practitioners. Sociology Mind, 8, 143-153.

https://doi.org/10.4236/sm.2018.82012

Received: February 7, 2018

Accepted: April 25, 2018

Published: April 28, 2018

Copyright $\odot 2018$ by author and Scientific Research Publishing Inc. This work is licensed under the Creative Commons Attribution International License (CC BY 4.0).

http://creativecommons.org/licenses/by/4.0/

\begin{abstract}
The idea that clinicians who are in recovery from addiction or substance abuse working as addiction practitioners seems deeply counter-intuitive. Compounding this is the problem that many have incurred criminal records, so the idea seems, at best nonsensical. Yet the cold hard essentialisms of professionalization and medicine gives way at times to the sophistry and serendipity of empiricism. These former sufferers know what they are talking about. The result is that there is an extremely high success rate in securing employment at practitioner, supervisor and management level as well as popularity with clients, due to them having a high affinity with lay experiences. This is an exploratory sociological article intended to raise some issues that present with the employment and training of recovering people as addiction practitioners. The tentative conclusions are that counsellors in recovery have a sophisticated awareness of the idiosyncrasies of the addiction field. However, of much more impact is the issue that they face challenges, related to matters of professionalization, stigma and the associated ongoing gentrification of the addiction field. There is a need for further research and emerging themes given the changing and reconfiguring nature of the health field and the wider neo-liberal political arena. They also possess a resilient and strength based wisdom not located in the over accessible neo-liberal vocabulary around these precepts but have experiences of the encounter with the Gethsemane understanding of deficit and purgatory; thereby the right to take back the stolen neo-liberal appropriation of resilience. They also importantly have access to alternative proven yet marginalised discourses that have stood the test of time.
\end{abstract}

\section{Keywords}

Gentrification, Twelve Steps: Professional Versus Personal Peer Baggage 


\section{Introduction}

There are acute dangers in attending to why a programme is successful. There is an imperative to know cause and effect thereby increase understandability, yet this has more to do with an ideology of modernity around the potency of linearity and rationality. Many of those who experience addiction conclude that rationality, though advantageous, are at times problematic, even fatal. For many the journey from addiction is a story of a battle with the internality of the comfort afforded by the use of substance, the subsequent witness to the dark night of the soul and then the externality of stigma and currently a professional requirement to have a superficial reading of a mantra around resilience. This is often a requirement in the steady gentrification involved in professionalization whereby older peer, traditional and affective wisdoms are superseded by highly rationalised instrumental wisdoms described by Weber (Van Manen, 1977). I intend to look at some of the issues that present themselves with regard to alcohol and drug clinicians are in recovery from addiction. In order to facilitate this I review the addiction field and historical models of addiction understandings to shed light on the issue. I also review a genealogy of the field and how clinical practice has changed, ostensibly due to clinical rationalisations but more likely due principally to structural reconfigurations in the field. Entering a new profession is also a step up into new power/knowledge hegemony, concerning what knowledge is gained but what knowledge is required to be relegated. We argue that recovering practitioners, partly due to their nonprofessional, non-expert yet empirical location can negotiate around the fickle network of privileged discourses.

\section{Preliminary Literature Review}

A very brief and preliminary literature review was carried around the subject of recovering clinicians and addressed challenges and benefits arising. Issues around past criminal offending were not addressed at this stage.

There were a number of themes arising itemised by Doukas \& Cullen (2010). These included risks of relapse, motivation for entering, disconnection from self-help groups, over-involvement with clients, over involvement with work and over identification with clients and the repercussions of relapse. I will attend to these later.

Hecksher (2007) attended to the challenges of dual relationships and specific dilemmas that may occur and issues around problems with objectivity (p. 1261). He refers to a setting in Denmark where "para-professionals as they are called, somewhat patronisingly)" work along-side professionally trained staff without recovery status i.e. those who hold BAs in social work, psychology etc. The advantages seen are "a former addict acting as a counsellor evocates a desirable objective for client" (p. 1254), however the "circumstances create a high risk of accentuating: dual relationships". However, he concluded that "a history of recovery can be seen as a resource not a barrier" (p. 1266).

Some literature addresses the interactional style locating an alleged dichotomy 
between confrontational and motivational approaches (Toriello \& Strohmer, 2004).

Toriello et al. (2004) writes on the impact of interactional style, recovery status, and nonverbal behaviour. An assumption around an ideal type that recovering practitioners adapt a very confrontative style was not played out in reality. In situations where funding pressures meant "addiction counsellors have less time to spend with clients' (p. 43.) 'this may lead to an interactional style that is a direct confrontational approach in order' to get down to business” (p. 43). However, this caricatured ideal type was not played out in reality. The authors add "Thombs and Osborn suggested that the recovering addiction counsellor's association with traditional intervention such as $\mathrm{CI}$, (confrontational interaction) is more a stereo-type, one that is not supported by their results or ours." (p. 52).

Moreover, a confrontation approach may be more identified with a group membership variable wherein the counsellor uses a style much more in common with the cultural milieu within the twelve step organisation. There is after all a difference in being confronted by a peer than a professional.

Issues that led to positive outcomes were expertness; attractiveness (was the counsellor likeable) and trustworthiness. He quotes one author English (1987) who "found that clients' perceived addiction counsellors with a history from addiction as more expert, attractive and trustworthy" (p. 46) however (Toriello, 2004) found no effect. Thombs and Osborn however made the point that "recovering addiction counsellors did not endorse the $\mathrm{CI}$ approach significantly more often than the MI approach" (p. 46), the author considers this surprising given the number of recovering addicts in the field in the field.

Culbreth (2000) reviewed 16 studies that investigated differences in counsellor with or without recovering status and came up with the following results.

a) Clients perceptions about counsellor and the effectiveness of treatment are not related to recovery status.

b) Counsellors who are in recovery view problems in different ways and use different treatment methods than non-recovering peers.

c) Recovering and non-recovering counsellors have different personality traits and attitudes.

\section{Themes and anecdotal responses.}

Some responses were given by people who deliver a degree course in addiction studies.

\subsection{Risks of Relapse}

Given the relapsing nature of the issue this is a real possibility, and it does happen from time to time. However, experience shows that the few who relapse often come back again and have gained much from the experience. Moreover, some students report that the classes form a part of a pastoral recovery support network. As such "triggers" (Stanley et al., 2000) are addressed and the reality of 
relapse is embraced as a learning opportunity. It is often said in twelve-step parlance despite a long period of recovery that recovering people are "only one drink away from relapse" (Wilson, 2013).

\subsection{Motivation for Entering}

Often recovering people are doing twelve-step works, i.e. "passing the message on" (Wilson, 2013). This is a double edged issue. They can be open to concerns around zealotry and also (although not as often verbalised), that of exploitation. A question left unasked here is what are seen to be valid reasons for entering. There seems to be an assumption that it more valid to have a non-peer vocation than a peer vocation, to attend more to the rational actor than the devoted actor discourse (Atran, 2016).

\subsection{Disconnection from Self-Help Groups}

This needs to be attended to in the initial interview of students and encouragement to make this possible and ongoing. It is also signalled in the imperative of putting limits but also expertise to institutional non-academic pastoral care.

\subsection{Over Involvement with Clients}

This is crucial and needs to be attended to by staff so that they model the correct boundaries. There is especial emphasis on the focus on the professional self as apart from the personal self. What needs to be reflected on is what is gained, what is lost in this transition. A prevailing theme is the phenomenon of dependence which can also involve over helping. Moreover this is a highly ethical concern in positions of power where dependency is often a two way street.

\subsection{Over Involvement with Work}

To a large extent this occurs because recovering clinicians see their role more as a vocation or calling rather than a job, complying with the category (Atran, 2016) of devoted actors rather than rational actors. There is an ongoing tension between the cold rational professional and those who do the task because it is somewhat of a spiritual calling.

\subsection{Over Identification with Clients}

Much of the training addresses issues such as transference and parallel process and a rigorous addressing of the need to fit intervention to the individual client needs. The key supervision issue often addressed in clinical supervision for addiction clinicians is "who's needs are being met?"

\subsection{Repercussion of Relapse}

This is a real concern yet surprisingly rare despite fears based on stigma of the field needs to honour these dangers in a robust and compassionate fashion. 


\section{Genealogy of Addiction Discourses}

"May you have a firm foundation."

"When the wind of changes shift" (Bob Dylan)

There is often a common sense myth around a Hegelian progress towards enlightenment in the clinical field reaching a goal of clinical perfection. In order to understand the importance of clinicians in recovery it is useful to address a genealogy of the addiction treatment field. We argue that the trajectory has been more of a story of reconfigurations in the field not due to clinical considerations but material economic considerations. This is explained more accurately by Marx than Hegel in his theory of dialectic materialism. That professionals comply with the idealist mythology is a concern that is habitually relegated. We also claim that one organisation that has bucked this trend has been the virulently peer based and non-expert based twelve step organisations. Many addiction professional in recovery belong to these organisations and often influenced their practices by these connections.

\subsection{The Moral Model}

In a refreshingly materialist view of addiction (May, 1997) describes how in colonial Britain "medicine and alcohol were drawn together to construct a new category of persons, which by the 1850s had acquired the label alcoholic." (May, 1997: p. 2). Socioeconomic conditions in the preceding century, in conjunction with a ban on French grain imports, provided incentives for technological developments in agriculture and machinery resulting in high grain surpluses. Gin became available at low prices. A dramatic increase in the dispersed population; resulting from the earlier Enclosure Acts produced a large landless peasantry and a period of "unparalleled urbanization and industrialization" (May, 1997: p. 2) and reports of large-scale drunkenness being commonplace. Emerging capitalist relations of production required a disciplined and skilled industrial urban work force. Alcohol misuse was universal, but construed, along with other behavioural problems as a moral failing cited within the, urban poor, due to their profligate and immoral ways. With affluent people, the phenomenon was viewed more as an idiosyncratic behaviour. The emerging middle classes from non-conformist protestant backgrounds favoured qualities like temperance and self-control and strong work orientations. One response for the unemployed was the workhouse. The role of this establishment was to enforce the work habit on a dispossessed humanity and "let the poor see and feel that their parish, although it will not allow them to perish ... is yet the hardest task master" (Mac Atasney, 1997: p. 6). In this context, the "political and economic conditions for defining alcohol misuse as a moral problem (were) already well established" (May, 1997: p. 3). The issue concerned sinfulness within the individual (host), who partook of addictive (substance).The cure was self-control, prayer, and abstinence, as befitting a capitalist (environment) ethos of self-control and rationality. 


\subsection{The Dispositional (Disease) Model}

However, the workhouse also eventually provided the means of medical gaze. This was a time of scientific medicalisation and a transition from older humoral, holistic means of thinking of disease, to newer ways of investigating external agents of disease. The humoral method recognized the role of external agents, but also importantly constructed disease in terms of elemental bodily balance. The information about this was, subjectively reported by the sufferer to the physician and used to provide diagnosis. However scientific medicine reduced the causation of disease to its external agent. Importantly, this "localized pathology in specific organs and lesions which could be examined by the doctor without reference to the patients view" (May, 1997: p. 4).

Along with other mental illnesses the expert view of the doctor became involved in matters, which previously had been construed as moral problems. Medical colonization was progressing so that "moral behaviour as a set of domains into which medicine could intrude" (May, 2001). "The dispositional disease model (often called the medical model) would cite the etiology as emanating from biological or genetic origins within the human body. In keeping with the modernist mode of thought the disease was thought to be possibly progressive, genetic and transferable. The only cure was abstinence, possibly supported by medication prescribed by an expert professional. The move to the dispositional model signalled a transition from 'bad' to 'mad.' and has been described as the susceptibility, culpability dichotomy" (Martin, 1999: p. 1), According to this dichotomy, wrongdoers (culpable) are responsible agents who warrant guilt and blame for actions they choose, whereas sick persons (susceptible) are victims who deserve compassion and therapy for the illness from which they suffer" (Martin, 1999: p. 1).

Although these two models were in some sense binary, in a susceptibility/culpability arrangement, they both posited the issue within the individual. This was an overwhelming theme in the emerging capitalist system.

\subsection{A Wildcard Diversion into the Peer Voice, the Twelve Step Model}

Fast forward to the 1930s in the US the completely peer based Alcoholics Anonymous organization was established, by two alcoholic gentlemen named Bill and Bob (surnames being anonymous). Engaging in some fancy footwork it functionally, combined elements of the dispositional model and the moral model, changing the term moral to spiritual factors. Importantly the organization used the disease concept, as a metaphor, or simile (i.e. like a disease). In any case one person's nomothetic category is another person's metaphor, what matters in the end is the power of the person who perpetuates the label. Common sense would suggest that there is more potency in the professional metaphor than the peer metaphor. However the peer metaphor provided somewhat of immunity to the insubstantiality of professional reconfigurations and still does. 
The rationale was that if alcoholism was constructed as a disease it followed that it was progressive, incurable, and therefore treatment, would be lifelong. It was therefore not a moral issue but a medical issue. Moreover the early members influenced by Jung and William James researched major religions and found common elements e.g. surrender to a higher power, confession and fellowship. There was a functionalism, in the movement that possibly was the key to its ground breaking effectiveness.

From its peer-based stance the organization was not in a position to investigate and settle a central issue, i.e. if indeed alcoholism was a disease or not. In any case the jury is still out on this matter among the esoteric community. AA however, preceded with a disease social construction as workable with a sense of the algebra of the issue, i.e. alcoholism is like a disease (let $\mathrm{x}=$ the unknown quantity). James simply took the empirical route, taking for granted the authenticity of reported spiritual experiences and taking a Durkheimian functional route, not investigating creedal content but recognising the imperative of social and moral bonds.

Importantly the movement operated within a counter mainstream moral discourse. To problematize the prevailing moral model which preached willpower and self-control, AA recommended a counter intuitive discourse of "letting go", and "acceptance" of the disease. In some ways the organization was more important in what it was not, rather than what it was.

The organization was focused on lay non-expert support. The disease was positioned as permanent, progressive and incurable but recoverable. The lexicon was deliberately paradoxical, i.e. recovery (a term also with spiritual overtones) was a life-long process yet, "one day at a time" (Wilson, 2013) indeed to "Give us this day our daily bread" (Christofferson, 2011). Members were encouraged to use the twelve steps, which formed the spiritual basis of the programme. Although the organization was heavily influenced by the modernist aspect of science, with the important concepts such as progress, it also emanated from a spiritual paradigm. The "belief" or myth in the presence of the disease was more important than any factual reality of such an entity. As Karen Armstrong (2004) writes to the effect that myths may be right or wrong, but they continue to happen.

The twelve-step movement also had a fiercely non-political aspect that was enshrined in the twelve traditions which included sanctions on bringing the name of AA into any disrepute. There were no representatives of AA and no one could speak on behalf of the organization. It was as such, subject to attack from professional discourse and could offer no symmetrical response, an earlier version of "rolling with resistance" (Markland et al., 2005) in mythical proportions. Yet being in the position of not responding to a question affords a strength in not entering the ascribed terms of the debate. Paradoxically the issue was cited in the individual yet the cure was in the collective. The most common pronoun in the twelve steps is the word "We". Moreover despite the movements timely reticence in avoiding the term religion, by transposing it into the inoffensive term 
spiritual. The recommendation was to "walk the walk" retaining the active rather than intellectual tenor of the movement. Abstract theology was insufficient, what was required for sobriety was action.

\section{Discussion Where to from Here? Surviving a Neoliberal Environment}

A common strategy in the strength based practice of motivational interviewing, is that after a certain time in the interview when key issues have been summarised is to ask the naïve question, where to form here? It is obviously not an easy question to answer but some matters can be raised.

\subsection{The End of Aetiology, Fixing the Deficit}

Modernity had a new-found confidence that science could explain everything, religion being designated as superstition to the aetiological scrap heap. Durkheimian functionalism envisaged the state's role was to fix the broken individual in order to furnish the modern nation. These projects would be divided, there being roles for the appropriate experts in a tidy division of labour, the psychiatrist for the biologically predisposed, the psychologist for those with emotional or behavioural flaws, in a comfortable division of labour. Yet there were assumptions in this project, such as

1) Aetiology is key

The idea around cause and effect, that knowledge thereof is of wonderful comfort. If the cause of an ailment could be found a cure could be provided. However, this certainty in the physical sciences was less in the social sciences. For many twelve-step adherents the cause was an interesting yet possibly irrelevant side show. It could be of a spiritual, genetic, origin, or maybe all or none of the above. It was seen as "cunning baffling and powerful" (Cheever, 2015).

2) There are flawed people

Maybe deriving from the Christian idea of original sin, the existence of deviant individuals provided the rationale for the relevant professionals that would make them ready for the capitalist workforce. Parsons (1975) described the sick role and the healer role. The outcome was to make them fully functioning members of the work force. The psychiatrist attended to the genetically flawed, the therapist to the emotionally flawed and the behavioural psychologist to the cognitively flawed. However the two-way nature of dependency was not within the vocabulary. The patient was dependent on the professional yet the professional thereby dependent on the sick individual. This reciprocity extended to the Meta level. The protective state depended on a proportion of sick individuals, as religion had depended on a proportion of sinful individuals.

3) Credentialed experts know best

Following on from the formulations that arose different professionals were employed in order to attend to the addiction issues. In most jurisdictions professional alcohol and drug clinicians usually are post graduates who obtain their addiction qualification at post graduate level. Their primary degree is in psy- 
chology, nursing, social work etc. The assumption that addiction is a less viable entity than mental health, or social welfare issues is an intriguing mystery. Many people with addiction/substance abuse issues recoil at the thought of going to a psychologist or social worker for help. Anecdotal responses abound with narratives around patronising professionals with book knowledge and an inability to discern between truth and reality when they are negotiated artfully by the skilful client.

\subsection{Reconfiguration of the Field, Hegel and Marx}

Hegel surmised that humanity would strive towards an ideal which would enlighten how we should live and thus progress was made. Marx inverted this declaring that how we live determines our ideals and as such progress is achieved or thwarted often at times deserting our nature as homo-faber committed to the reproduction of our fellow species. Currently we are living in an ideology of virulent neo-liberalism. The morality ascribed for us, under the mantras of neo-liberalism, which we freely avow is the declining social state. In our liberal obfuscation we claim that the practices in the addiction field are progressing towards an ideal counselling transaction. On an unspoken level we comply with an agenda to save money so our identity concurs with Foucaultian category of, homo-economous (Read, 2009). The modernist idea of flawed people has now been abandoned. There are very strong sanctions against the use of deficit language.

Newer strength based practices such as Motivational interviewing, avoid any cause/effect paradigm as they disburse regimes of self-empowerment and self-management. In a startling paradox, Marx got it right and wrong at the same time. He surmised that the state would wither away under conditions of socialism, however the state is withering away under conditions of late capitalism.

\subsection{Hidden Curriculum}

The concept of the hidden curriculum emanating from a neo-Marxist approach, refers to the unintended effects of the education system in the perpetuating of norms and values of capitalism. It postulated that what students are taught is not always what they learn. In the learning of professionalisation for the addiction field there are readily accessible vocabularies that construct and perpetuate a caricatured stereotypical view of the 12 step practioners. For example, they are constructed as being more inherently confrontational than motivational, despite evidence that this is more of a caricature (Toriello, 2004). Newer strength based practices are privileged and welcomed into the new vocabulary yet they are based less on old Freudian and Christian cathartic ideas that release subjectivity (the truth shall set you free) but more on the production of subjectivities conducive to a neo-liberal environment.

\subsection{Professional Baggage versus Peer Baggage}

The road to gentrification involves the gaining of esteem and the provision of a salaried position; in effect the person achieves the status of a rational actor. A 
part of the hidden curriculum in the journey of professional development is to forgo old twelve step baggage, in effect to desert the category of devoted actor. A recovering past is often constructed in the professionalization process as an encumbrance. There are valid reasons for this, however never addressed is the concept of professional baggage and its openness to neo-liberal ideology.

\section{Conclusion}

In the subjugated addiction field recovering clinicians avoid an acute sense of their own alienation as they readily ascribe clinical justification to other dominant narratives. Consequently, the neo-liberal narrative is not open to problematisation. Yet periodically those who achieve resilience, rather than have it ascribed to them, through a holy encounter with the dark night of the soul, maybe have a depth of wisdom that escapes us all. Nevertheless what they avow should be on our professional agenda.

\section{Afterthought, Resilience the Price of Experience}

My mental health worker, hearing of my desire to do an addiction degree said "you will relapse under the pressure of study". My counsellor urged me to apply for jobs less stressful, a degree needs high intelligence I listened well to their advice.

Annie $K$, recovering alcoholic

At the end of this year I will receive my degree. I have had one $C$ grade one $B$ grade, all the rest were $A$ including $A+s, I$ 'm glad I Ignored their advice.

Annie K, Bachelor of Addiction Studies

\section{References}

Armstrong, K. (2004). A Short History of Myth (Vol. 1). Edinburgh: Canongate Books.

Atran, S. (2016). The Devoted Actor: Unconditional Commitment and Intractable Conflict across Cultures. Current Anthropology, 57, No. S13. https://doi.org/10.1086/685495

Cheever, S. (2015). My Name Is Bill: Bill Wilson-His Life and the Creation of Alcoholics Anonymous. New York: Simon and Schuster.

Christofferson, D. T. (2011). Give Us This Day Our Daily Bread. Church Educational System Fireside.

Culbreth, J. R. (2000). Substance Abuse Counselors with and without a Personal History of Chemical Dependency: A Review of the Literature. Alcoholism Treatment Quarterly, 18, 67-82. https://doi.org/10.1300/J020v18n02_05

Doukas, N., \& Cullen, J. (2010). Recovered Addicts Working in the Addiction Field: Pitfalls to Substance Abuse Relapse. Drugs: Education, Prevention and Policy, 17, 216-231. https://doi.org/10.3109/09687630802378864

Hecksher, D. (2007). Former Substance Users Working as Counselors. A Dual Relationship. Substance Use \& Misuse, 42, 1253-1268. https://doi.org/10.1080/10826080701446711

Mac Atasney, G. (1997). This Dreadful Visitation, the Famine in Lurgan/Portadown. 
Dublin: Beyond the Pale Publications.

Markland, D., Ryan, R. M., Tobin, V. J., \& Rollnick, S. (2005). Motivational Interviewing and Self-Determination Theory. Journal of Social and Clinical Psychology, 24, 811-831. https://doi.org/10.1521/jscp.2005.24.6.811

Martin, M. W. (1999). Alcoholism as Sickness and Wrongdoing. Journal for the Theory of Social Behaviour, 29, 109. https://doi.org/10.1111/1468-5914.00094

May, C. (1997). Habitual Drunkards and the Invention of Alcoholism: Susceptibility and Culpability in Nineteenth (p. 169). Addiction Research, Abingdon-on-Thames: Gordon \& Breach Science Publishers Inc.

May, C. (2001). Pathology, Identity and the Social Construction of Alcohol Dependence. Sociology, 35, 385-401. https://doi.org/10.1177/S0038038501000189

Parsons, T. (1975). The Sick Role and the Role of the Physician Reconsidered. The Milbank Memorial Fund Quarterly. Health and Society, 53, 257-278.

Read, J. (2009). A Genealogy of Homo-Economicus: Neoliberalism and the Production of Subjectivity. Foucault Studies, No. 6, 25-36. https://doi.org/10.22439/fs.v0i0.2465

Stanley, B., \& Standen, P. J. (2000). Carers' Attributions for Challenging Behaviour. British Journal of Clinical Psychology, 39, 157-168. https://doi.org/10.1348/014466500163185

Toriello, P. J., \& Strohmer, D. C. (2004). Addictions Counselors' Credibility: The Impact of Interactional Style, Recovery Status, and Nonverbal Behavior. Journal of Addictions \& Offender Counseling, 25, 43-57. https://doi.org/10.1002/j.2161-1874.2004.tb00192.x

Van Manen, M. (1977). Linking Ways of Knowing with Ways of Being Practical. Curriculum Inquiry, 6, 205-228. https://doi.org/10.1002/j.2161-1874.2004.tb00192.x

Wilson, B. (2013). Alcoholics Anonymous: Big Book. https://www.ebookit.com/tools/bp/Bo/eBookIt 